\title{
Short- and Long-Intracortical Inhibition in Incomplete Spinal Cord Injury
}

\author{
Yiqun P. Mi, Aaron Z. Bailey, Aimee J. Nelson
}

\begin{abstract}
Background: Short- (SICI) and long-interval intracortical inhibition (LICI) are involved in the control of movement and movement initiation. Alterations to the two circuits can result in direct alterations to the physiology of the muscles and can be used to explain the physiological changes to individuals with spinal cord injury (SCI). Objective: To probe changes in GABAergic function by characterizing the recruitment curves of SICI and LICI interval intracortical inhibition in an upper limb muscle in chronic SCI participants with injury between C3 and C7. Methods: Recruitment curves were elicited with conditioning stimulus intensities determined as a percentage of active motor threshold (AMT) (SICI, 60\% to 110\% AMT; LICI, 90\% to 130\% AMT) and recorded from the flexor carpi radialis muscle during an isometric contraction equal to $15 \%$ to $20 \%$ of maximum voluntary contraction. Results: AMT was greater and motor-evoked potential sizes were lower in SCI compared with uninjured controls. SICI magnitude was not different between groups, although the range of conditioning stimulus intensities to evoke SICI was unique to each group. LICI was reduced in the control group during active contraction and remained present in SCI. Discussion: LICI was increased in the actively contracted flexor carpi radialis

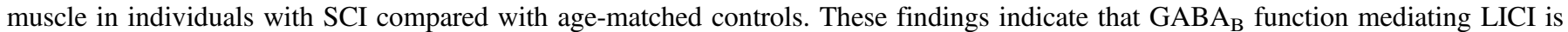
different in SCI versus controls. Conclusions: Increased LICI in SCI may be attributed to the medication baclofen or to changes in the neural mechanisms controlling contraction-related modulation of the LICI circuit.
\end{abstract}

RÉSUMÉ: Inhibition intracorticale courte et longue dans le traumatisme spinal incomplet. Contexte: L'inhibition intracorticale à intervalle interstimulus court et à intervalle long (SICI et LICI) est impliquée dans le contrôle et le début du mouvement. Une altération des deux circuits peut mener à des altérations directes de la physiologie musculaire et peut expliquer les changements physiologiques observés chez les individus présentant un traumatisme de la moelle épinière (TME). Objectif: Le but de l'étude était d'examiner les changements de la fonction GABA ergique en caractérisant les courbes de recrutement de SICI et de LICI au niveau d'un muscle du membre supérieur chez des patients présentant un TME entre C3 et C7 en phase chronique. Méthode: Les courbes de recrutement ont été élicitées au moyen d'intensités de stimulus conditionnant déterminées comme étant un pourcentage du seuil moteur actif (SMA) (SICI, 60\% à 110\% SMA; LICI, 90\% à 130\% SMA) et enregistrées au niveau du muscle grand palmaire pendant une contraction isométrique égale à $15 \%$ à $20 \%$ de la contraction volontaire maximale. Résultats: Le SMA était plus élevé et les potentiels évoqués moteurs étaient plus bas chez les sujets présentant un TME par rapport aux sujets témoins sans lésion. Bien que l'écart des intensités du stimulus conditionnant pour évoquer le SICI ait été propre à chaque groupe, l'ampleur de SICI n'était pas différente entre les groupes. Le LICI était diminué chez le groupe témoin pendant la contraction active et demeurait présent chez les sujets du groupe TME. Discussion: Le LICI était augmenté dans le muscle grand palmaire en contraction chez les sujets atteints d'un TME par rapport à celui de sujets témoins appariés pour l'âge. Ces observations indiquent que la fonction GABA ergique dans le LICI est différente chez les sujets atteints d'un TME par rapport aux sujets témoins. Conclusions: Une augmentation de LICI dans le TME peut être attribuée au traitement par le baclofen ou à des changements dans les mécanismes neuronaux contrôlant la modulation de la contraction du circuit de LICI.

Keywords: contraction, flexor carpi radialis, LICI, muscle, SCI, SICI, TMS

doi:10.1017/cjn.2015.310

Can J Neurol Sci. 2016; 43: 183-191

Extensive modifications to ascending somatosensory pathways, descending motor pathways, and sensorimotor cortices follow incomplete spinal cord injury (SCI). ${ }^{1,2}$ Following experimentally induced deafferentation, inhibitory GABAergic cortical activity in sensorimotor cortices is reduced, ${ }^{3-5}$ which is thought to mediate rapid cortical plasticity. ${ }^{3,6}$ In SCI, reductions in GABAergic cortical activity are suggested to promote rapid functional gains. ${ }^{7}$ However, there is evidence of sustained alterations in cortical inhibition, ${ }^{8,9}$ which may lead to alterations in GABA-mediated or GABA-modulated motor cortical circuitry.

Short-interval intracortical inhibition (SICI) is an inhibitory motor cortical circuit evoked by a subthreshold transcranial magnetic stimulation (TMS) pulse (i.e. conditioning stimulus [CS]) followed by a suprathreshold TMS pulse (i.e. test stimulus [TS]). When the TS follows the CS by 1 to $5 \mathrm{~ms}$, the motor-evoked potential (MEP) is suppressed. ${ }^{10}$ SICI is thought to be cortically mediated $^{11}$ via $\mathrm{GABA}_{\mathrm{A}}$ receptor transmission ${ }^{12-14}$ because late and not early indirect waves (I-waves) are inhibited. ${ }^{11,15}$ These data suggest that SICI modifies intracortical neuron activity, which inhibits the I-3 and later I-waves instead of acting directly on the pyramidal neurons, which results in a net reduction of the

\footnotetext{
From the Department of Kinesiology, McMaster University, Hamilton, Canada. Received November 26, 2014. Final Revisions Submitted May 13, 2015. Correspondence to: Aimee J. Nelson, Department of Kinesiology, McMaster University, 1280 Main Street West, Hamilton, ON L8S 4L8. E-mail: nelsonaj@mcmaster.ca.
} 
corticospinal output to the spinal cord. In controls, SICI is modulated in advance of and during active muscle contraction and is therefore suggested to participate in the control of movement. ${ }^{16-18}$

In incomplete SCI, the depth of SICI is reduced in the actively contracted tibialis anterior (TA) muscle when compared with controls, although the circuit is elicited at similar intensities in the two groups. ${ }^{19}$ The same report also indicates the presence of SICI in the contracted first dorsal interosseous muscle, although it is unknown how this differs from uninjured populations, and specifically in SCI with cervical injury. Collectively, these data contribute to the hypothesis that cortical inhibition is reduced as a result of incomplete SCI and suggest an altered state of $\mathrm{GABA}_{\mathrm{A}}$-mediated transmission. However, in SCI, it remains unknown whether the SICI profile is abnormal in a muscle of the upper limb such as the flexor carpi radialis (FCR) muscle. In our experience, chronic incomplete tetraplegia with injury ranging from $\mathrm{C} 3$ to $\mathrm{C} 7$ retains the ability to perform isometric contraction of the FCR muscle, albeit this ability varies greatly across individuals. This is an important experimental consideration because reliably evoked MEPs of discernable amplitude typically require SCI participants to actively contract the targeted muscle. The present study is focused on FCR, a muscle important in wrist control to achieve grasping, pulling, and writing, ${ }^{20}$ movements that may be lost as a result of cervical SCI. ${ }^{7}$

Long-interval intracortical inhibition (LICI) is elicited by a suprathreshold CS depressing the MEP evoked by a subsequent suprathreshold TS delivered 50 to $200 \mathrm{~ms}$ later. $^{21,22}$ Cervical epidural recordings of descending corticospinal volleys suggest a cortical origin for the LICI circuit; later I-waves of the second suprathreshold stimulus are significantly reduced at interstimulus intervals (ISIs) of 100 to $150 \mathrm{~ms}$, whereas the early I-wave is unaltered. ${ }^{23-25}$ LICI appears to be mediated via GABA $_{B}$ receptors such that baclofen ${ }^{26}$ and other drugs acting on GABA transmission increase LICI. ${ }^{27,28}$ One study demonstrated that LICI can be elicited in SCI at rest and continues to persist during active contraction of first dorsal interosseous. ${ }^{29}$ However, in SCI, the LICI recruitment profile remains unknown.

It was hypothesized that uninjured control participants would exhibit SICI at CS intensities of 70\%, 80\%, and 90\% AMT as described in other studies. ${ }^{10,16}$ In accordance with Roy et al, (2011) who studied SICI in the TA muscle in SCI, we hypothesized SICI to exist at CS of $80 \%$ AMT, thus representing a narrow range of SICI recruitment. It was further hypothesized that LICI would exist in uninjured controls at suprathreshold intensities (i.e. 100\%, $110 \%, 120 \%$, and $130 \%$ AMT). ${ }^{30}$ In SCI, we hypothesize LICI to exist at a reduced range of only the highest CS intensity (i.e. 130\% AMT), in support of the very large intensity required to elicit LICI in SCI elsewhere. ${ }^{29}$

In this study, we obtained SICI and LICI recruitment curves from the contracted FCR muscle in incomplete cervical SCI and age-matched controls. Thorough characterization of the intracortical inhibitory circuits following incomplete SCI is important for determining changes in motor cortical GABAergic transmission. Identifying aberrations within intracortical GABAergic circuits is fundamental for experimental approaches that promote plasticity in motor cortex to improve arm function in SCI.

\section{METHODS \\ Participants}

Eight incomplete SCI (mean age, 29.5 years; standard deviation, 6.7; seven males; eight right-handed participants) and thirteen agedmatched uninjured individuals (mean age, 28.8 years; standard deviation, 5.6; eight males; nine right-handed participants) participated. Because of the asymmetry of the lesion location and the heterogenic nature of the damage to the spinal cord following SCI, each limb from a SCI participant was treated as an independent limb, resulting in the participation of 13 SCI limbs. Demographic, lesion, and medication information for all SCI participants is found within Table 1. SCI limbs that were unable to perform the required isometric contraction were excluded from analysis. All participants provided written informed consent and the study was approved by the Office of Research Ethics at McMaster University and conformed to the Declaration of Helsinki.

\section{Electromyography}

Muscle activity was recorded using 9-mm diameter silversilver chloride surface electrodes with the active electrode being

Table 1: Demographics of participants

\begin{tabular}{l|c|c|c|c|c|l|c}
\hline Participant ID & Age & $\begin{array}{c}\text { Injury } \\
\text { level }\end{array}$ & $\begin{array}{c}\text { Years } \\
\text { postinjury }\end{array}$ & $\begin{array}{c}\text { Cause of } \\
\text { injury }\end{array}$ & ASIA & Medications & $\begin{array}{c}\text { AMT } \\
\text { (MSO) }\end{array}$ \\
\hline P001 & 27 & C4-C5 & 7 & Traumatic & C & Baclofen & $41 \%$ \\
\hline P002 & 26 & C3 & 2 & Traumatic & C & Baclofen & $40 \%$ \\
\hline P004 left & 24 & C5-C6 & 2.5 & Traumatic & C & Baclofen, Soflax, Gabapentin, Pantoprazole, Senokot, Detrol & $26 \%$ \\
\hline P004 right & & & & & & & $27 \%$ \\
\hline P006 left & 38 & C5 & 14 & Traumatic & B & Axid, Colace, Ditropan, Baclofen & $39 \%$ \\
\hline P006 right & & & & & & & $36 \%$ \\
\hline P007 right & 27 & C3-C4 & 7 & Traumatic & B & Fentanyl patch, Pregabalin, Baclofen, Tizanidine, Oxybutynin, \\
P008 left & 22 & C5 & 9 & Traumatic & D & Benadryl, Percocet & $32 \%$ \\
\hline P008 right & & & & & & & $34 \%$ \\
\hline
\end{tabular}

The age of subject, the number of years after the subject sustained a spinal cord injury measured at the time of the experiment, and the cause of injury are shown; sides tested are indicated as left or right flexor carpi radialis and medications taken by subjects are also listed. AMT, active motor threshold; ASIA, American Spinal Injury Association; MSO, mean stimulator output. 
placed over the muscle belly of the FCR and the reference electrode placed over the tendon at the wrist. The ground electrode was placed over the medial styloid process at the wrist. Electromyography (EMG) was amplified at $1000 \times$ gain, bandpass filtered (20 to $2.5 \mathrm{kHz}$, Intronix Technologies Corporation Model 2024F, Bolton, Ontario, Canada) and digitized (5 kHz, Micro 1401, Cambridge Electronics Design, Cambridge, UK). Signal software (v5, Cambridge Electronic Design Limited, Cambridge, $\mathrm{UK}$ ) was used to acquire and analyze EMG data.

\section{Maximum Voluntary Contraction}

To determine the maximum voluntary contraction (MVC) for FCR, participants were asked to maximally contract the forearm during wrist flexion. Three trials (each 3 seconds) separated by 18 seconds of relaxation were performed. This duration of intertrial rest sufficiently allowed the maximum EMG to be obtained in each subsequent trial (see the following analysis). MVC was calculated as the rectified area of a 38-ms window that fell within their maximum contraction period during each of the three trials. In cases where participants expressed discomfort from the high stimulation intensity (i.e. $80 \%, 90 \%$, or $100 \%$ mean stimulator output [MSO]), one trial rather than three would be acquired for the recruitment curves. The duration of $38 \mathrm{~ms}$ was chosen to allow direct comparison with background EMG measured during SICI and LICI testing as described in the following section. SICI and LICI recruitment curves were obtained during active isometric contraction of $15 \%$ to $20 \%$ MVC in FCR in all participants. As reported elsewhere, resting MEPs tend to be small or absent in many individuals with SCI; thus, all responses were evoked during a tonic contraction. ${ }^{19,31}$

\section{TMS}

TMS was delivered using a custom built $50-\mathrm{mm}$ diameter figure-of-eight branding coil connected to a Magstim 200 stimulator (Magstim, Whitland, UK). The position and orientation of the coil was monitored throughout the experiment using Brainsight Neuronavigation (Rogue Research, Montreal, Canada) with optical sensors placed on the coil and the participant. The same TMS coil was used for all measures in both experiments. The TMS coil delivered a monophasic pulse over the optimal location to elicit MEPs in the relaxed FCR at $45^{\circ}$ in relation to the parasagittal plane to induce a posterolateral to anteromedial current in the cortex. The motor hotspot was defined at this location and was where all subsequent measures were taken.

The active motor threshold (AMT) of the SCI group was defined as the stimulator intensity which resulted in MEPs $50 \mu \mathrm{V}$ larger than the background EMG in 5 of 10 consecutive trials during a constant contraction of $20 \%$ MVC in FCR. The age-matched control participants were then asked to maintain a constant contraction equal to $20 \% \mathrm{MVC}$ of the SCI match participant (using the voltage of the EMG); similarly, AMT was defined as $50 \mu \mathrm{V}$ larger than the background EMG in 5 of 10 consecutive trials. Although this approach equates the magnitude of AMT based on matched EMG contraction, it remains unclear whether perceived exertion to achieve the $20 \%$ MVC was similar between groups.

\section{MSO Required to Elicit a Rectified Area Equal to Half of the Maximum}

The maximum MEP in $\mathrm{mV}^{*} \mathrm{~ms}$ was defined as the largest rectified area in a 70-ms window following the TMS artifact and was identified by increasing the MSO in $10 \%$ increments from $10 \%$ to $100 \%$ area was measured to avoid ambiguities in identifying peaks within polyphasic MEPs that are characteristic of the FCR muscle. ${ }^{32}$ Three trials were typically obtained at each increment and averaged. $\mathrm{MEP}_{\text {halfmax }}$ was defined as the $\mathrm{MSO}$ required to elicit a rectified area equal to half of the maximum. $\mathrm{MEP}_{\text {halfmax }}$ was recorded and confirmed in 10 subsequent trials.

\section{SICI and LICI}

During SICI and LICI testing, the EMG representing $15 \%$ to $20 \%$ MVC from FCR was displayed as a bright line on an oscilloscope; participants were required to match the position of the FCR EMG controlled line to the 20\% MVC target line. Background EMG was calculated as the rectified area of the first $38 \mathrm{~ms}$ of each trial window, the length of time from the start of the trial to the onset of TMS stimulation, and expressed as a percent of MVC that was also acquired over a 38-ms window.

SICI in FCR was tested at a CS-TS ISI of $3 \mathrm{~ms}$. Thirteen SCI limbs and 13 control limbs were tested. The CS was delivered at intensities of $60 \%, 70 \%, 80 \%, 90 \%, 100 \%$, and $110 \%$ AMT. For all participants, the TS intensity was set to elicit $\mathrm{MEP}_{\text {halfmax }}$ as performed elsewhere. ${ }^{19,31}$ This allows the TS to be set at an intensity that enables either suppression or facilitation of the MEP to be observed, a choice pertinent to studies in SCI where MEPs are generally reduced. Fifteen conditioned MEPs (i.e. $\mathrm{MEP}_{\mathrm{CS}-\mathrm{TS}}$ ) were collected for each CS intensity and 15 unconditioned MEPs $\left(\mathrm{MEP}_{\mathrm{TS}}\right)$ were collected. The CS intensities were tested in separate blocks and the order of blocks was randomized for each participant. Consecutive stimuli were delivered every 5 seconds.

LICI in FCR was tested at a CS-TS ISI of $150 \mathrm{~ms}$. Twelve SCI limbs and 13 control limbs were tested. The CS was delivered at an intensity of $90 \%, 100 \%, 110 \%, 120 \%$, and $130 \%$ AMT. TS intensity was set at $\mathrm{MEP}_{\text {halfmax }}$. ISI of $150 \mathrm{~ms}$ has been shown to evoke strong LICI for CS intensities between $100 \%$ and $120 \%$ MT. ${ }^{21}$ Similar to SICI, 15 conditioned MEPs were acquired for each CS intensity and 15 unconditioned MEPs were acquired. CS intensities were tested in separate blocks and the block order was randomized. Consecutive stimuli were delivered every 5 seconds.

\section{Analysis}

MEPs were measured as the rectified area of the EMG response in a 70-ms window following the TMS artifact. Normalized $\mathrm{MEP}$ areas (i.e. $\mathrm{MEP}_{\mathrm{CS}-\mathrm{TS}} / \mathrm{MEP}_{\mathrm{TS}}$ ) were subjected to a two-way analysis of variance (ANOVA) with between-subject factor groups (two levels: control and SCI) and within-subject factor CS intensity (SICI with six levels: 60\%, 70\%, 80\%, 90\%, $100 \%$, and $110 \%$ AMT; LICI with five levels: $90 \%, 100 \%, 110 \%$, $120 \%$, and $130 \%$ AMT). To test the hypothesis that SICI and LICI exist at CS intensities that typically evoke these circuits (SICI: CS $70 \%, 80 \%$, and 90\%; LICI: $120 \%$ and $130 \%$ ), Bonferroni corrected a priori $t$-tests compared the unnormalized unconditioned MEP area (i.e. $\mathrm{MEP}_{\mathrm{TS}}$ ) versus the unnormalized conditioned MEP area (i.e. $\mathrm{MEP}_{\mathrm{CS} \text {-TS }}$ ). Further, between-group differences were compared using Bonferroni corrected a priori $t$-tests at $90 \%$ AMT (SICI) and at $120 \%$ and $130 \%$ AMT (LICI). Post-hoc Tukey's test was used to test for significant main and/or interaction effects following ANOVAs. MVC was analyzed in a two-way repeated measure ANOVA with within factor blocks (three levels: blocks 1, 2, and 3) and between-factor groups (two levels: control 

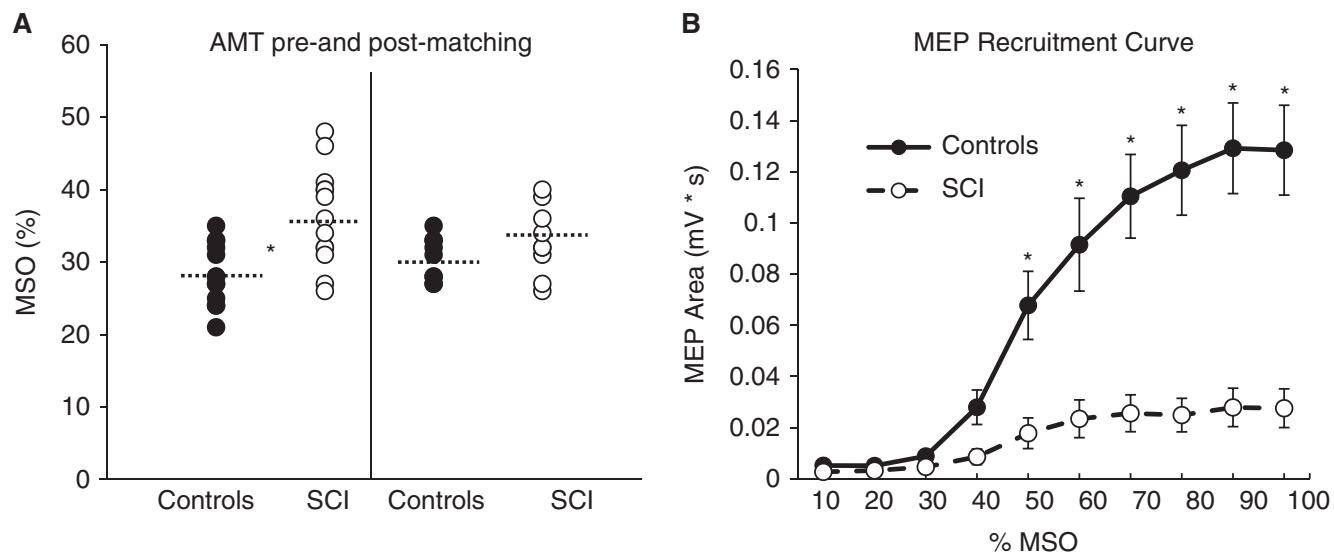

Figure 1: (A) Active motor threshold (AMT) of controls and spinal cord injury (SCI; left). Prematching showed significantly greater AMT in SCI than controls (right). Matching the AMT values between the two groups removed any effects caused by differences in conditioning stimulus (CS) intensity because of AMT on short(SICI) and long-interval intracortical inhibition (LICI). *Significant differences between the two groups. The dashed line represents the average AMT for either controls or SCI. (B) Motor-evoked potential (MEP) recruitment curves of AMT matched controls and SCI. Group-averaged MEP area data for all ten stimulator intensities. *Differences between the control and SCI groups observed at all intensities greater than 50\% MSO.

and SCI). Background EMG was tested using the previous two-way ANOVA statistical model. MEP recruitment curves were analyzed in a two-factor ANOVA with between-subject factor groups (two levels: control and SCI) and within-subject factor intensities (10 levels: 10 through $100 \mathrm{MSO}$ ). To test whether SCI participants experienced fatigue over the course of the testing session, background EMG was further analyzed as a function of the factor time (five levels: blocks 1 through 5). Effect sizes were calculated using Cohen's D. If the assumptions of sphericity were not met, Greenhouse-Geisser corrections were used. Statistical significance was set at $\mathrm{p}<0.05$.

\section{RESULTS}

EMG during MVC was not different between groups, as revealed by two-way ANOVA $\left(\mathrm{F}_{(1,16)}=0.415, \mathrm{p}=0.529\right)$ ( $\mathrm{SCI}$, $30.08 \pm 31.9 \mathrm{mV}^{*} \mathrm{~ms}$; control, $\left.38.22 \pm 18.8 \mathrm{mV}^{*} \mathrm{~ms}\right)$. Likewise, there was no difference in MVC among the three blocks $\left(F_{(2,32)}=0.144, p=0.866\right)$. One-way repeated measures ANOVA indicated that participants with SCI did not fatigue over the duration of the experiment (time, $\mathrm{F}_{(2.216,36.146)}=2.072$, $\mathrm{p}=0.138$ ). Background EMG was lower in SCI compared with controls (SCI, $2.75 \pm 0.56 \mathrm{mV}^{*} \mathrm{~ms}$; control, $4.34 \pm 0.37 \mathrm{mV} * \mathrm{~ms}$; unpaired two-tailed $t$-test; $\mathrm{p}=0.033$ ). However, relative EMG, normalized to individual MVCs, was not different between groups (SCI, $24 \pm 7.1 \%$; control, $22 \pm 2.9 \%$; unpaired two-tailed $t$-test; $\mathrm{p}=0.76$ ), indicating that both groups of participants were exerting the same percent of their maximum output of their muscles. The group-averaged MSO (with standard deviation) for delivery of the TS (i.e. unconditioned MEP) was $44 \pm 6 \%$ in controls and $47 \pm 7 \%$ MSO in SCI. The MSO values were not statistically different (two-tailed, unpaired $t$-test, $\mathrm{p}=0.33$ ). A clear peak-to-peak unconditioned MEP was observable in six SCI participants (nine limbs). From these individuals, the peak-to-peak MEP amplitude ranged from $\sim 1$ to $6 \mathrm{mV}$; however, all analyses were performed on the MEP area.

AMT was significantly greater in SCI compared with controls (SCI, $36 \pm 6.8 \% \mathrm{MSO}$; control, $28 \pm 1.1 \% \mathrm{MSO}$; unpaired two-tailed $t$-test; $\mathrm{p}=0.002$ ). Because the effects of SICI and LICI can be explained by the higher CS intensity used in participants with SCI, we analyzed SICI and LICI data only from participants in whom the range of AMT overlapped. The AMT matching criterion was designated as any AMT values that fell within 2 standard deviations of the group-averaged mean AMT of the uninjured controls. Any AMT values from either group that fell outside of that range were excluded from further analysis. Therefore, nine SCI limb data $(n=6$ SCI participants) and nine aged-matched controls with similar AMT values (SCI, $33 \pm 4.8 \%$ MSO; control, $30 \pm 3.0 \%$ MSO; unpaired two-tailed $t$-test; $\mathrm{p}=0.20$ ) were subsequently analyzed and the AMT values for all participants pre- and post-AMT matching are shown in Figure 1A. This procedure therefore controlled for group differences in CS intensities that could affect the depth of SICI and LICI. Figure 1B displays the group-averaged MEP recruitment curve for SCI and controls (AMT matched). Two-way ANOVA revealed an effect of INTENSITY $\left(\mathrm{F}_{(1.396,22.337)}=41.784, \mathrm{p}<0.01\right)$ and an intensity $x$ group interaction $\left(\mathrm{F}_{(1.396,22.337)}=18.654, \mathrm{p}<0.01\right)$. Post-hoc Tukey's revealed greater MEP area in controls versus SCI at all intensities $\geq 50 \%$ MSO ( $\mathrm{p}<0.05)$.

\section{SICI}

Nine SCI limbs and nine controls were included in the analysis of the SICI experiment. Figure 2A displays representative SICI data from an uninjured control and an SCI participant displaying a U-shaped recruitment curve for both groups. $\mathrm{MEP}_{\text {halfmax }}$ was significantly greater in controls versus SCI (control, $45.12 \pm 20.89 \mathrm{mV}^{*} \mathrm{~ms} ; \quad$ SCI, $16.97 \pm 10.04 \mathrm{mV} * \mathrm{~ms}$; unpaired two-tailed $t$-test; $\mathrm{p}=0.0036)$. The group-averaged recruitment profile of SICI, graphing the normalized MEP data in control and SCI participants during an isometric contraction is shown in Figure 2B. Two-way ANOVA revealed no effect of CS $\left(\mathrm{F}_{(1.79,28.71)}=3.267, \mathrm{p}=0.057\right)$ or group $\left(\mathrm{F}_{(1,16)}=0.039, \mathrm{p}=0.846\right)$ or CS*GROUP interactions $\left(\mathrm{F}_{(1.79,28.71)}=1.08, \mathrm{p}=0.347\right)$. For uninjured controls, a priori Bonferroni corrected $t$-tests revealed the presence of SICI at all three hypothesized CS intensities of 
A

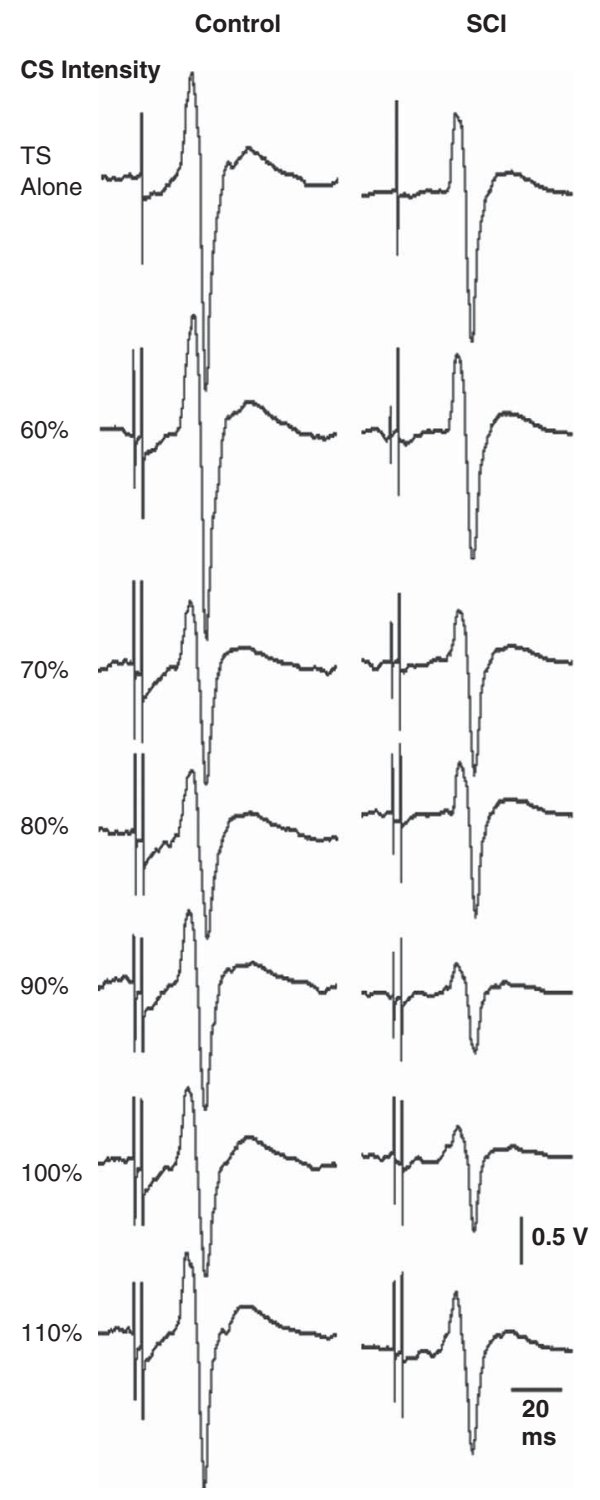

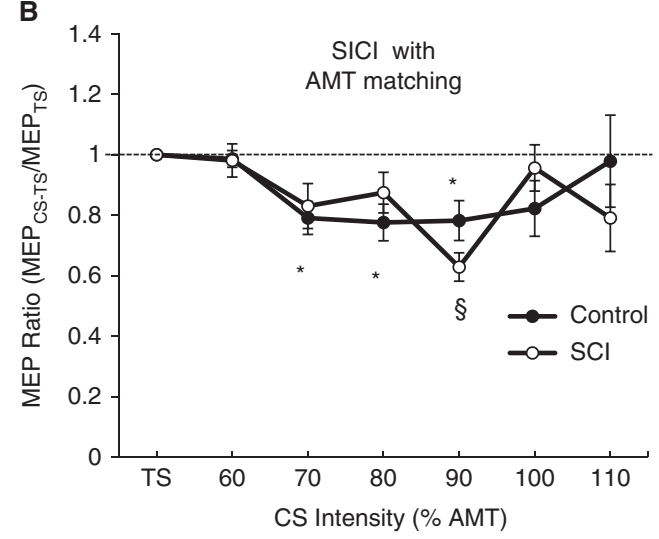

C

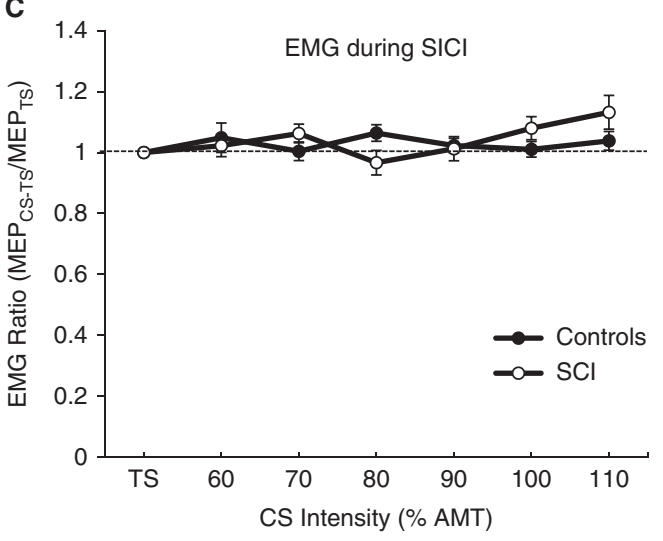

D

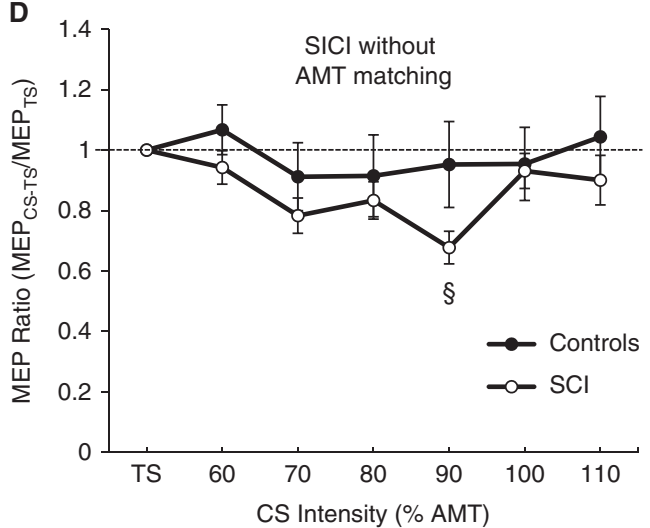

Figure 2: Short-interval intracortical inhibition (SICI). (A) Raw traces of SICI recruitment in controls and spinal cord injury (SCI). (B) SICI recruitment curves of controls and SCI with active motor threshold (AMT) matching between groups. Group-averaged motor-evoked potential (MEP) data (with standard error) normalized to the unconditioned MEP for each of the conditioning stimulus (CS) intensities. Symbols represent differences between the unconditioned and conditioned MEP within the control group (*) and within the SCI group (\$), indicating presence of SICI. (C) SICI background electromyelography (EMG) of controls and SCI. Group-averaged EMG ratio data (with standard error) normalized to the EMG of the unconditioned state for all CS intensities. (D) SICI recruitment curves of controls and SCI without AMT matching ( $n=13$, both groups). Group-averaged MEP data (with standard error) normalized to the unconditioned MEP for each of the CS intensities. Group-averaged MEP data (with standard error) normalized to the unconditioned MEP for each of the CS intensities. Symbols represent differences between the unconditioned and conditioned MEP within the SCI group (\$) indicating presence of SICI.

$70 \%$ (one-tailed paired $t$-test, $\mathrm{p}=0.01$, Cohen's $\mathrm{D}=0.5$ ), $80 \%$ (one-tailed paired $t$-test, $\mathrm{p}=0.014$, Cohen's $\mathrm{D}=0.47$ ), and $90 \%$ (one-tailed paired $t$-test, $\mathrm{p}=0.013$, Cohen's $\mathrm{D}=0.5$ ) AMT. For SCI,
SICI was not present at $70 \%$ (one-tailed paired $t$-test, $\mathrm{p}=0.105$ ) or $80 \%$ AMT (one-tailed paired $t$-test, $\mathrm{p}=0.082$ ), but did demonstrate SICI at $90 \%$ AMT (one-tailed paired $t$-test, 
A

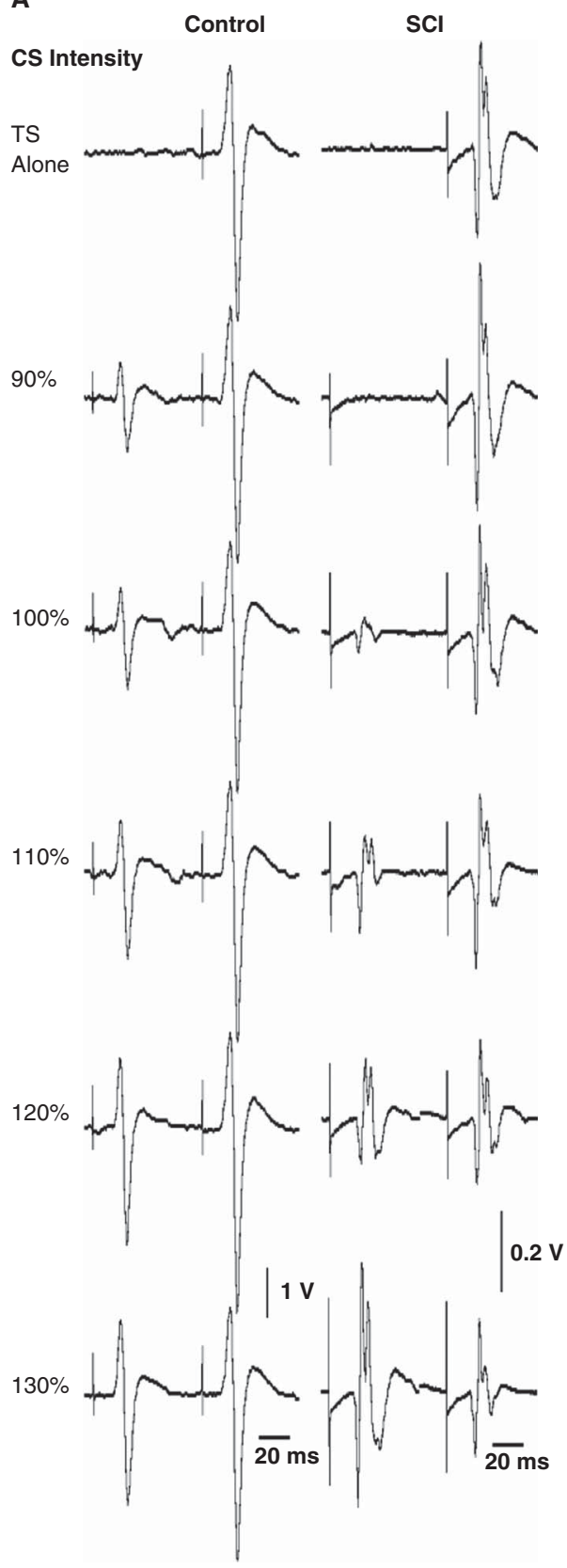

B

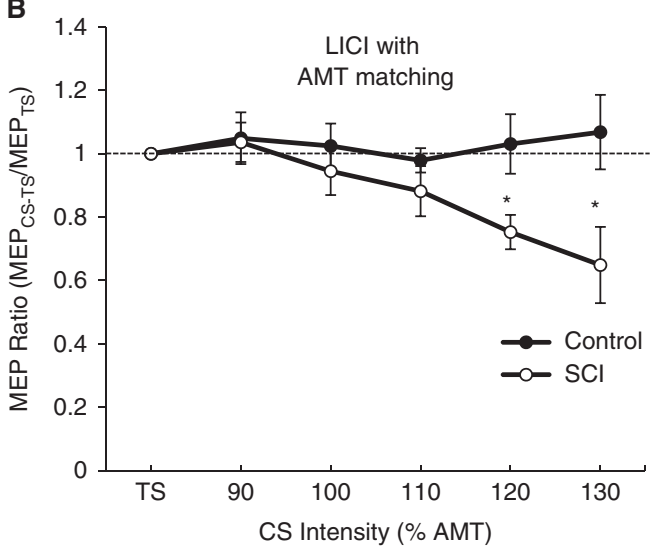

C
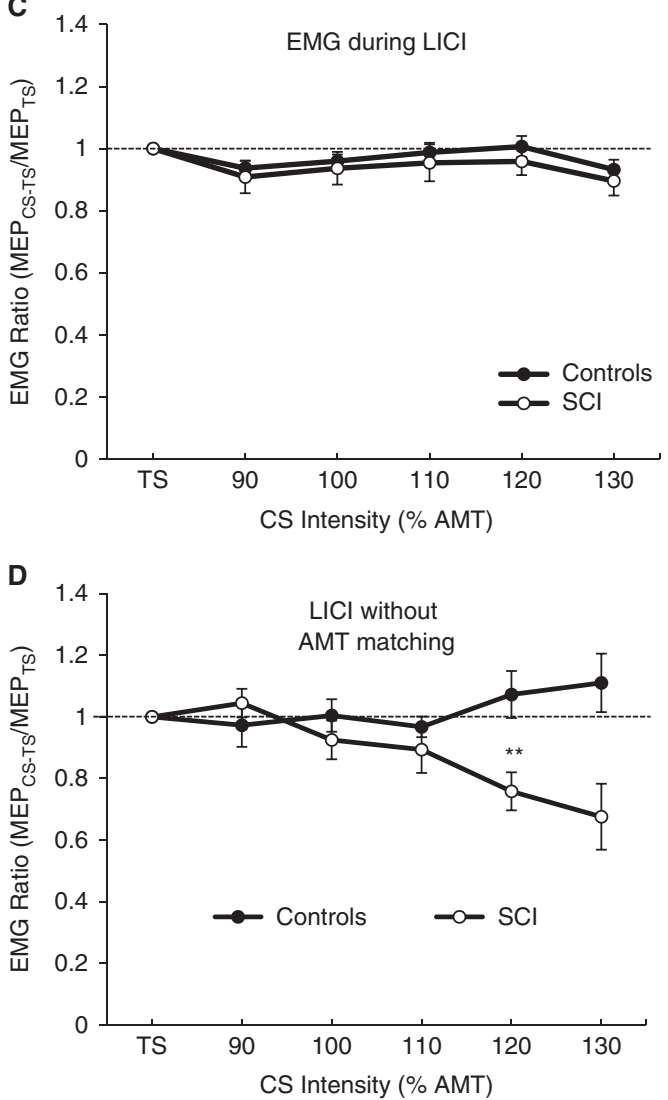

Figure 3: Long-interval intracortical inhibition (LICI). (A) Raw traces of LICI recruitment in controls and spinal cord injury (SCI). (B) LICI recruitment curves of controls and SCI with active motor threshold (AMT) matching between groups. Group-averaged motor-evoked potential (MEP) data (with standard error) normalized to the unconditioned MEP for each of the conditioning stimulus (CS) intensities. Control MEP ratios are significantly different from SCI MEP ratios at $120 \%$ and $130 \%$. *Significant differences between the two groups. (C) Active short-interval intracortical inhibition (SICI) background electromyelography (EMG) of controls and SCI. Group-averaged EMG ratio data (with standard error) normalized to the EMG of the unconditioned state for all CS intensities. (D) LICI recruitment curves of controls and SCI without AMT matching. Group-averaged MEP data (with standard error) normalized to the unconditioned MEP for each of the CS intensities. Control MEP ratios are significantly different from SCI MEP ratios at $120 \%$ and $130 \%$. *Significant differences between the two groups.

$\mathrm{p}=0.0043$, Cohen's $\mathrm{D}=0.46)$. Similar to the analysis performed elsewhere, ${ }^{19}$ we subsequently tested differences between SCI and controls at $90 \%$ AMT and revealed no significant differences between the two groups (two-tailed paired $t$-test, $\mathrm{p}=0.086$ ).
Group-averaged background EMG is shown in Figure 2C and two-way ANOVA revealed no effect of CS $\left(\mathrm{F}_{(5,120)}=1.017\right.$, $\mathrm{p}=0.41)$ or group $\left(\mathrm{F}_{(1,24)}=0.375, \mathrm{p}=0.55\right)$ or $\mathrm{CS} \times$ group interaction $\left(\mathrm{F}_{(5,120)}=2.049, \mathrm{p}=0.08\right)$. In addition to AMT matching 
analysis was performed on the complete dataset, without AMT matching and is shown in Figure $2 \mathrm{D}(\mathrm{n}=13$, both groups). Similar to the above, the two-way ANOVA revealed no effect of CS $\left(\mathrm{F}_{(2.06,49.42)}=2.856, \mathrm{p}=0.066\right)$, group $\left(\mathrm{F}_{(1,24)}=1.197, \mathrm{p}=0.29\right)$, or $\mathrm{CS} \times$ group interaction $\left(\mathrm{F}_{(2.06,49.42)}=0.886, \mathrm{p}=0.42\right)$. For uninjured controls, SICI was not present at any CS intensity. Similar to the "matched" data, SICI was only present at $90 \%$ AMT for SCI (one-tailed paired $t$-test, $\mathrm{p}=0.0009$ ) and there no statistical differences between SCI and control at the $90 \%$ AMT (two-tailed paired $t$-test, $\mathrm{p}=0.10$ ).

\section{LICI}

Nine SCI limbs and nine controls were included in the analysis of the LICI experiment. Figure 3A displays representative LICI data from an uninjured control and an SCI participant displaying an increase in inhibition with increase in CS intensity for SCI and no LICI in control participants. $\mathrm{MEP}_{\text {halfmax }}$ was significantly greater in controls than SCI (control, $47.13 \pm 20.66 \mathrm{mV}^{*} \mathrm{~ms}$; SCI, $16.09 \pm 7.47 \mathrm{mV}^{*} \mathrm{~ms}$; unpaired two-tailed $t$-test; $\mathrm{p}=0.0017$ ). The group-averaged recruitment profile of LICI graphing the normalized MEP data in control and SCI participants during an isometric contraction is shown in Figure 3B. Two-way ANOVA revealed no effect of $\mathrm{CS}\left(\mathrm{F}_{(2.46,39.29)}=2.627, \mathrm{p}=0.074\right)$, but demonstrated significant effect of group $\left(\mathrm{F}_{(1,16)}=4.353, \mathrm{p}=0.05\right)$ and $\mathrm{CS} \times$ group interaction $\left(\mathrm{F}_{(2.46,39.29)}=3.404, \mathrm{p}=0.035\right)$. A priori Bonferroni corrected $t$-tests test revealed LICI in SCI at CS intensities of $120 \%$ (one-tailed paired $t$-test, $\mathrm{p}=0.003$, Cohen's $\mathrm{D}=0.48$ ) and near significance at $130 \%$ (one-tailed paired $t$-test, $\mathrm{p}=0.03$ ) AMT. No LICI was observed in uninjured controls at either $120 \%$ (one-tailed paired $t$-test, $\mathrm{p}=0.48$ ) or $130 \%$ (one-tailed paired $t$-test, $\mathrm{p}=0.44$ ) AMT. Differences between controls and SCI were observed at $120 \%$ (one-tailed paired $t$-test, $\mathrm{p}=0.012$ ) and $130 \%$ AMT (one-tailed paired $t$-test, $\mathrm{p}=0.012$ ). Figure 3C displays the group-averaged background EMG for each CS intensity normalized to the background EMG of the unconditioned MEP. The two-way ANOVA performed for the background EMG revealed no effect of CS $\left(\mathrm{F}_{(4,92)}=1.319\right.$, $\mathrm{p}=0.27)$, group $\left(\mathrm{F}_{(1,23)}=0.957, \mathrm{p}=0.34\right)$, and no $\mathrm{CS} \times$ group interaction $\left(\mathrm{F}_{(4,92)}=0.032, \mathrm{p}=0.99\right)$. The data without AMT matching is shown in Figure $3 \mathrm{D}(\mathrm{n}=13$, both groups). Similar to the "matched AMT" results, two-way ANOVA revealed no significance of CS intensity $\left(\mathrm{F}_{(4,92)}=1.347, \mathrm{p}=0.26\right)$, but demonstrated significant effects of group $\left(\mathrm{F}_{(1,23)}=5.248\right.$, $\mathrm{p}=0.031)$ and $\mathrm{CS} \times$ group $\left(\mathrm{F}_{(4,92)}=6.835, \mathrm{p}<0.001\right)$. Post-hoc Tukey's test revealed differences between the SCI and controls at CS intensities of $120 \%(p=0.001)$ and $130 \%(p<0.001)$ AMT. Follow-up paired two-tailed $t$-tests were performed at the different CS intensities to identify the presence of the LICI circuit within either the control or SCI groups. Controls did not demonstrate LICI at $120 \%(p=0.66)$ or $130 \%(p=0.60)$ AMT. In contrast and similar to the "matched AMT" analysis, SCI demonstrate LICI circuit at both $120 \%(p=0.007)$ and $130 \%(p=0.028)$ AMT.

\section{DISCUSSION}

In this study, we observed higher AMT and lower $\mathrm{MEP}_{\text {halfmax }}$ in the SCI participants compared with the uninjured controls. However, the relative background contraction was not different between the two groups. Because of the differences in AMT between the two groups, a subset of SCI data was used that allowed AMT matching such that group differences in SICI and LICI cannot be attributed to differences resulting from greater CS intensities in one group compared with the other. In SCI, SICI was evoked at a CS intensity of 90\% AMT only. Uninjured controls demonstrated SICI at all three hypothesized CS intensities. Our findings confirm previous observations in the TA muscle of controls and in chronic tetraplegia, where the range of SICI recruitment appears to be different. ${ }^{19}$ With an isometric contraction of the FCR muscle, LICI remains intact in SCI but is absent within controls. Previous reports have observed LICI to occur in both uninjured and postspinal cord injured participants at a very high CS intensity during an isometric contraction. ${ }^{29}$ Contrary to these observations, our data demonstrate that none of the hypothesized suprathreshold CS intensities elicited LICI in uninjured controls while LICI was observed in SCI at the highest CS intensity tested. The persistence of LICI in SCI alludes to an altered function of this circuit in the presence of muscle activity.

\section{AMT and MEPs}

The increase in $\mathrm{AMT}^{19,33,34}$ and decrease in $\mathrm{MEPs}^{35}$ are consistent with previous literature on the changes to these measurements following an injury to the spinal cord. These changes are likely attributed to the decreases in corticospinal output because of injury.

\section{SICI}

The magnitude of SICI in the contracted FCR muscle was not different between SCI and controls. However, we did observe that the range of CS intensities capable of evoking significant SICI within each group were different. In controls, CS intensities of $70 \%, 80 \%$, and 90\% AMT evoked significant SICI. In SCI, however, the only CS intensity to evoke significant SICI was $90 \%$ AMT. These data suggest that SICI in FCR may indeed be observed in SCI but requires a relatively high CS intensity. These data support a previous finding whereby SICI was only observed in the TA muscle in SCI using a CS intensity at $80 \%$ AMT, whereas a larger range of CS intensities (60\% to $90 \%$ AMT) evoked SICI in controls. ${ }^{19}$ However, these authors also report greater SICI in controls versus SCI, an effect we did not observe. This difference can be attributed to the specific muscle tested (TA vs FCR). One mechanism to explain the high CS intensity required to evoke SICI in SCI relates to reductions in GABA concentration and/or $\mathrm{GABA}_{\mathrm{A}}$-mediated transmission. As reported elsewhere, damage to ascending pathways leads to reductions in GABA concentration in sensorimotor cortices ${ }^{3-5}$ and this may contribute to neural plasticity following injury. ${ }^{3,6}$ Such reductions in intracortical GABA concentration are likely to accompany SCI as suggested elsewhere. ${ }^{7,19}$ Further, SICI is reduced in the presence of the $\mathrm{GABA}_{\mathrm{B}}$ receptor agonist baclofen ${ }^{26}$ through presynaptic $\mathrm{GABA}_{\mathrm{B}}$ receptors inhibiting $\mathrm{GABA}_{\mathrm{A}}$ interneurons, ${ }^{36}$ which is a common medication in our SCI population. Because SICI is reduced because of presynaptic $\mathrm{GABA}_{\mathrm{B}}$ autoinhibition, ${ }^{26,27,37}$ baclofen may be responsible for our observation that SICI was only observed at 90\% AMT CS intensity in participants with SCI. Therefore, it is unclear whether the high CS requirement in SCI relates to decreases in GABA concentration and/or the inhibition of $\mathrm{GABA}_{\mathrm{A}}$ receptors via baclofen, and both of these sources may contribute to reductions in SICI in our SCI population. 


\section{LICI}

Controls exhibited typical LICI behavior in the presence of an isometric contraction; little to no inhibition caused by LICI $^{18}$ likely via the reduction of the cortical excitability controlling the LICI circuit. Compared with controls, SCI participants showed greater LICI during contraction at the highest CS intensities used. One study investigated the contraction-related modulation of LICI in controls, in SCI taking baclofen and also in SCI not taking baclofen. ${ }^{29}$ Their data demonstrate modulation of LICI such that the SCI group on baclofen showed modulations that parallel those in controls, namely a contraction-related reduction in LICI. In contrast, the SCI group not taking baclofen did not show contraction-related modulation of LICI. In our study, we exposed group differences that appear similar to the control versus nonbaclofen group in Barry et al (2013). However, it is difficult to make direct comparisons with the latter report since within-group effects of contraction-related modulation are exposed rather than differences between groups.

One possible explanation for the presence of LICI in SCI compared with the absence of LICI in controls might be attributed to the effects of baclofen as almost all of the SCI participants were taking baclofen. Baclofen is a $\mathrm{GABA}_{\mathrm{B}}$ agonist and serves to increase $\mathrm{GABA}_{\mathrm{B}}$ transmission within the motor cortex. ${ }^{26}$ Increasing $\mathrm{GABA}_{\mathrm{B}}$ transmission likely results in an increase in LICI. $^{26}$ The mechanism of LICI involves $\mathrm{GABA}_{\mathrm{B}}$ receptormediated interneurons ${ }^{26}$ which act to inhibit I3- and later I-waves elicited by the TS, ${ }^{23-25}$ resulting in inhibition of the MEP. ${ }^{38}$ Facilitating these interneurons by increasing $\mathrm{GABA}_{\mathrm{B}}$ transmission results in a greater inhibition of the I3- and later I-waves, which results in decreased summation of the corticospinal volleys at the level of the spinal cord and a decreased MEP. Alternatively, it is possible that there are abnormalities in the movement-related modulation of LICI that may have arisen following an injury to the spinal cord. Because the movement-related modulation of SICI has been hypothesized to be a result of changes to cortical excitability, ${ }^{16,17}$ a similar mechanism can also be hypothesized for the movement-related modulation of LICI. Because SCI has been observed to result in reductions in GABA concentration within the sensorimotor cortices, ${ }^{3-5}$ it is a possibility that SCI can also affect the excitability of the primary motor cortex.

\section{Technical Considerations}

One important issue to consider in TMS studies in SCI is the reduction in the corticospinal output elicited by TMS. We attempted to match the groups' unconditioned MEP by selecting an intensity that fell on the sensitive portion of the recruitment curve (i.e. $\mathrm{MEP}_{\text {halfmax }}$ ). However, this resulted in higher absolute MEP values for the control group. Therefore, the effect of the CS on the TS may be different between groups and may lead to a greater opportunity for conditioning effects to be observed in the group with the lower unconditioned MEP area. Therefore, one limitation is that our findings in SCI may relate to the absolute unconditioned MEP area that was, compared with controls, smaller and therefore may have been more easily conditioned by the CS. Increasing the TS amplitude from 1 to $2 \mathrm{mV}$ reduces LICI $(100 \mathrm{~ms})$, but does not alter SICI. ${ }^{39}$ It is unclear whether such changes occur in LICI using $150 \mathrm{~ms}$ ISI. However, the possibility remains that group differences in LICI may relate to larger and smaller TS MEP amplitudes obtained in controls and SCI, respectively (Figure 1B). Additionally, other reports indicate that increasing the TS amplitude from 0.2 to $1 \mathrm{mV}$ result in an increase in SICI strength. ${ }^{36,40,41}$ However, increasing the TS intensity from 1 to $2 \mathrm{mV}$ decreases SICI strength. ${ }^{13,37}$ Last, one inherent difficulty in studying SCI involves the range of prescribed medications that cannot be withdrawn without caution. Therefore, we have studied individuals in their normally medicated state similar to other studies. ${ }^{19,31}$ Further, we did not have access to many SCI participants who were not taking baclofen and thus were unable to explicitly study the contribution of baclofen to the SICI and LICI circuits. Future studies may consider assessing the relationship between the magnitude of SICI/LICI and baclofen dosage.

\section{Conclusions}

The present study investigated LICI in the contracted FCR muscle in controls and individuals with SCI. Our main finding is that LICI is increased in individuals with SCI compared with controls and we suggest that baclofen and/or impairment in contraction-related modulation may provide plausible explanations for this effect. Further, the present research benefited from the use of a recruitment curve to elucidate the profile of intracortical inhibitory circuits in SCI, and we observed similarities and differences among our groups that may have been missed with the use of a single CS intensity. These findings have advanced our knowledge of the motor cortical changes that accompany chronic SCI and research focused on rehabilitative strategies in SCI populations may consider interventions focused on restoring contraction-related modulation of LICI for the ultimate purpose of improving arm function.

\section{DISCLOSURES}

AJN received funding from the Natural Sciences and Engineering Research Council of Canada. YPM, AB, and AN have nothing to disclose.

\section{REFERENCES}

1. Levy WJ, Amassian VE, Traad M, Cadwell J. Focal magnetic coil stimulation reveals motor cortical system reorganized in humans after traumatic quadriplegia. Brain Res. 1990;510:130-4.

2. Curt A, Bruehlmeier M, Leenders KL, Roelcke U, Dietz V. Differential effect of spinal cord injury and functional impairment on human brain activation. J Neurotrauma. 2002;19:43-51.

3. Levy LM, Ziemann U, Chen R, Cohen LG. Rapid modulation of GABA in sensorimotor cortex induced by acute deafferentation. Ann Neurol. 2002;52:755-61.

4. Hendry SH, Jones EG. Reduction in number of immunostained GABAergic neurones in deprived-eye dominance columns of monkey area 17. Nature. 1986;320:750-3.

5. Welker E, Soriano E, Van der Loos H. Plasticity in the barrel cortex of the adult mouse: effects of peripheral deprivation on GADimmunoreactivity. Exp Brain Res. 1989;74:441-52.

6. Jacobs KM, Donoghue JP. Reshaping the cortical motor map by unmasking latent intracortical connections. Science. 1991;251: 944-947.

7. Smith HC, Savic G, Frankel HL, Ellaway PH, Maskill DW, Jamous MA, et al. Corticospinal function studied over time following incomplete spinal cord injury. Spinal Cord. 2000; 38:292-300.

8. Smith HC, Davey NJ, Savic G, Maskill DW, Ellaway PH, Jamous MA, et al. Modulation of single motor unit discharges using magnetic stimulation of the motor cortex in incomplete spinal cord injury. J Neurol Neurosurg Psychiatry. 2000;68:516-20. 
9. Shimizu T, Hino T, Komori T, Hirai S. Loss of the muscle silent period evoked by transcranial magnetic stimulation of the motor cortex in patients with cervical cord lesions. Neurosci Lett. 2000;286:199-202.

10. Kujirai T, Caramia MD, Rothwell JC, Day BL, Thompson PD, Ferbert A, et al. Corticocortical inhibition in human motor cortex. J Physiol. 1993;471:501-9.

11. Di Lazzaro V, Restuccia D, Oliviero A, Profice P, Ferrara L, Insola A, et al. Magnetic transcranial stimulation at intensities below active motor threshold activates intracortical inhibitory circuits. Exp Brain Res. 1998;119:265-8.

12. Ziemann U, Lonnecker S, Steinhoff BJ, Paulus W. The effect of lorazepam on the motor cortical excitability in man. Exp Brain Res. 1996;109:127-35.

13. Ilic TV, Meintzschel F, Cleff U, Ruge D, Kessler KR, Ziemann U. Short-interval paired-pulse inhibition and facilitation of human motor cortex: the dimension of stimulus intensity. J Physiol. 2002;545:153-67.

14. Ziemann U, Lonnecker S, Steinhoff BJ, Paulus W. Effects of antiepileptic drugs on motor cortex excitability in humans: a transcranial magnetic stimulation study. Ann Neurol. 1996;40:367-78.

15. Hanajima R, Ugawa Y, Terao Y, Sakai K, Furubayashi T, Machii K, et al. Paired-pulse magnetic stimulation of the human motor cortex: differences among I waves. J Physiol. 1998;509:607-18.

16. Ridding MC, Taylor JL, Rothwell JC. The effect of voluntary contraction on cortico-cortical inhibition in human motor cortex. J Physiol. 1995;487(Pt 2):541-8.

17. Reynolds C, Ashby P. Inhibition in the human motor cortex is reduced just before a voluntary contraction. Neurology. 1999;53:730-5

18. Sohn YH, Wiltz K, Hallett M. Effect of volitional inhibition on cortical inhibitory mechanisms. J Neurophysiol. 2002;88:333-8.

19. Roy FD, Zewdie ET, Gorassini MA. Short-interval intracortical inhibition with incomplete spinal cord injury. Clin Neurophysiol. 2011;122:1387-95

20. Brorsson S, Nilsdotter A, Thorstensson C, Bremander A. Differences in muscle activity during hand-dexterity tasks between women with arthritis and a healthy reference group. BMC Musculoskelet Disord. 2014;15:154.

21. Valls-Sole J, Pascual-Leone A, Wassermann EM, Hallett M. Human motor evoked responses to paired transcranial magnetic stimuli. Electroencephalogr Clin Neurophysiol. 1992;85:355-64.

22. Wassermann EM, Samii A, Mercuri B, Ikoma K, Oddo D, Grill SE, et al. Responses to paired transcranial magnetic stimuli in resting, active, and recently activated muscles. Exp Brain Res. 1996; 109:158-63.

23. Nakamura H, Kitagawa H, Kawaguchi Y, Tsuji H. Intracortical facilitation and inhibition after transcranial magnetic stimulation in conscious humans. J Physiol. 1997;498:817-23.

24. Chen R, Lozano AM, Ashby P. Mechanism of the silent period following transcranial magnetic stimulation. Evidence from epidural recordings. Exp Brain Res. 1999;128:539-42.

25. Di Lazzaro V, Oliviero A, Mazzone P, Pilato R, Saturno E, Insola A, et al. Direct demonstration of long latency cortico-cortical inhibition in normal subjects and in a patient with vascular parkinsonism. Clin Neurophysiol. 2002;113:1673-9.
26. McDonnell MN, Orekhov Y, Ziemann U. The role of GABA(B) receptors in intracortical inhibition in the human motor cortex. Exp Brain Res. 2006;173:86-93.

27. Werhahn KJ, Kunesch E, Noachtar S, Benecke R, Classen J. Differential effects on motorcortical inhibition induced by blockade of GABA uptake in humans. J Physiol. 1999;517:591-7.

28. Pierantozzi M, Marciani MG, Palmieri MG, Brusa L, Galati S, Caramia MD, et al. Effect of Vigabatrin on motor responses to transcranial magnetic stimulation: an effective tool to investigate in vivo GABAergic cortical inhibition in humans. Brain Res. 2004; 1028:1-8

29. Barry MD, Bunday KL, Chen R, Perez MA. Selective effects of baclofen on use-dependent modulation of GABAB inhibition after tetraplegia. J Neurosci. 2013;33:12898-907.

30. McNeil CJ, Martin PG, Gandevia SC, Taylor JL. Long-interval intracortical inhibition in a human hand muscle. Exp Brain Res. 2011;209:287-97.

31. Roy FD, Yang JF, Gorassini MA. Afferent regulation of leg motor cortex excitability after incomplete spinal cord injury. J Neurophysiol. 2010;103:2222-33.

32. Byblow WD, Stinear CM, Smith MC, Bjerre L, Flaskager BK, McCambridge $\mathrm{AB}$. Mirror symmetric bimanual movement priming can increase corticomotor excitability and enhance motor learning. PLoS One. 2012; 7:e33882.

33. Davey NJ, Smith HC, Savic G, Maskill DW, Ellaway PH, Frankel HL. Comparison of input-output patterns in the corticospinal system of normal subjects and incomplete spinal cord injured patients. Exp Brain Res. 1999;127:382-90.

34. Freund P, Rothwell J, Craggs M, Thompson AJ, Bestmann S. Corticomotor representation to a human forearm muscle changes following cervical spinal cord injury. Eur J Neurosci. 2011; 34:1839-46.

35. Edwards DJ, Cortes M, Thickbroom GW, Rykman A, Pacsual-Leone A, Volpe BT. Preserved corticospinal conduction without voluntary movement after spinal cord injury. Spinal Cord. 2013;51:765-7.

36. Sanger TD, Garg RR, Chen R. Interactions between two different inhibitory systems in the human motor cortex. J Physiol. 2001;530:307-17.

37. Florian J, Muller-Dahlhaus M, Liu Y, Ziemann U. Inhibitory circuits and the nature of their interactions in the human motor cortex a pharmacological TMS study. J Physiol. 2008;586:495-514.

38. Paulus W, Classen J, Cohen LG, Large CH, Di Lazzaro V, Nische M, et al. State of the art: pharmacologic effects on cortical excitability measures tested by transcranial magnetic stimulation. Brain Stimul. 2008;1:151-63.

39. Udupa K, Ni Z, Gunraj C, Chen R. Effect of long interval interhemispheric inhibition on intracortical inhibitory and facilitatory circuits. J Physiol. 2010;588:2633-41.

40. Daskalakis ZJ, Christensen BK, Chen R, Fitzgerald PB, Zipursky RB, Kapur S. Evidence for impaired cortical inhibition in schizophrenia using transcranial magnetic stimulation. Arch Gen Psychiatry. 2002;59:347-54.

41. Wagle-Shukla A, Ni Z, Gunraj CA, Bahl N, Chen R. Effects of short interval intracortical inhibition and intracortical facilitation on short interval intracortical facilitation in human primary motor cortex. J Physiol. 2009;587:5665-78. 